\title{
Transition in environmental governance in the Brazilian Amazon: emergence of a new pattern of socio-economic development and deforestation
}

- Isabelle Tritsch ${ }^{a,}$,

- $\underline{\text { Damien Arvor }}$,

- $\quad$ a Université Sorbonne Nouvelle - Paris 3, UMR 7227 - Centre de Recherche et de Documentation sur les Amériques (CREDA), 28 rue Saint-Guillaume, 75007 Paris, France

- $\quad{ }^{b}$ LETG-Rennes-COSTEL UMR CNRS 6554, Université Rennes 2, Place du Recteur Henri Le Moal, 35043 Rennes Cedex, France

Received 6 June 2016, Revised 15 September 2016, Accepted 19 September 2016, Available online 29 September 2016 http://www.sciencedirect.com/science/article/pii/S0264837716305774

http://dx.doi.org/10.1016/i.landusepol.2016.09.018

\section{Highlights}

-We emphasize the end of the boom-and-bust development pattern in the Brazilian Amazon.

-Deforestation and socio-economic development follow an inverted U-shape relationship.

- Household incomes are greater in stabilized areas than in areas undergoing deforestation.

- Environmental governance efforts fostered the emergence of EKC.

\section{Abstract}

Socio-economic development in the Brazilian Amazon is currently reaching national averages although deforestation activity has been declining for a decade. As a consequence, recent studies rejected the widely agreed boom-and-bust development hypothesis that deforestation first generates an economic boom, which is then followed by a collapse as forest resources are depleted. Here, we confirm these studies that there is no boom-bust cycle and suggest that a new pattern of relationship between deforestation and socioeconomic development has emerged following an environmental Kuznets curve (EKC). In this scenario, environmental degradation increases in the early stages of economic development and decreases in later stages as the economy develops and wellbeing increases. To validate this assumption, we conducted the first sub-municipal analysis of socio-economic development and deforestation in the Brazilian Amazon for the 2000-2010 period. Our results confirm the emergence of an EKC relationship with a turning point beyond which socio-economic growth does not appear anymore to be a driver of deforestation. We also emphasize that areas subjected to active deforestation in 2010 present lower socio- 
economic indicators than stabilized areas, pointing to the precarious socio-economic situation of areas still undergoing active deforestation. We put these results in perspective by considering Brazilian efforts to ensure a transition in environmental governance with the objective of promoting land use sustainability through control of deforestation at the same time as supporting socio-economic development.

\section{Keywords}

- Brazilian Amazon;

- Deforestation;

- Socio-economic development;

- Environmental Kuznets curve;

- Boom-bust cycles;

- Environmental governance

\section{Introduction}

Socio-economic development across the Brazilian Amazon is a controversial research topic. In the late 2000s, seminal studies evidenced a boom-and-bust development pattern (Rodrigues et al., 2009, Celentano and Veríssimo, 2007 and Celentano et al., 2012). That is, timber extraction and the conversion of forests into cropland and pasture generate a boom in incomes and jobs in the first years of land occupation, which is then followed by a collapse as forest resources and soil fertility are depleted (Sears et al., 2007). This scenario recalls the historical pattern of economic development in the Amazon when the cycles of extraction of forest products used to follow a boom-and-bust pattern, characterized either by a rapid rise and decline in market prices or by the depletion of resource stocks. Associated with high deforestation rates over the past four decades, the boom-and-bust pattern may be considered as a lose-lose scenario from a long term perspective since it generates high environmental costs and limited socio-economic benefits (Weinhold et al., 2015).

Yet, the last decade has been marked by a dramatic decrease in deforestation rates in the Brazilian Amazon (Nepstad et al., 2014 and Arima et al., 2014) and a significant increase in the Human Development Index (HDI) (Caviglia-Harris et al., 2016). As a consequence, important recent studies reviewed the originally widely accepted boom-and-bust development hypothesis. Weinhold et al. (2015) evidenced that pre- and post-frontier municipalities in $\mathbf{2 0 0 0}$ have enjoyed an equal increase in their Human Development Index (HDI) across the Amazon during the last decade. Caviglia-Harris et al. (2016) asserted that socio-economic welfare has become decoupled from environmental factors and is converging to rising national averages.

While these studies provide evidence that deforestation has not been followed by a socioeconomic decline and thus reject the boom-and-bust hypothesis in the Brazilian Amazon, they provide little insight into the current scenario of socio-economic development and deforestation across the Amazon. In this paper, we suggest that the increased socio- 
economic development associated with a decrease in deforestation activity emphasizes profound changes on the land-use frontier and attests to the emergence of an environmental Kuznets curve (EKC). The EKC hypothesis predicts that environmental degradation may have an inverted U-shaped relationship with development: environmental degradation goes along with development until primary needs are met; then a turning point is reached when concerns for the environment increase and environmental degradation decreases (Dinda, 2004 and Pfaff and Walker, 2010).

To validate this assumption, we conducted the first sub-municipal analysis of socio-economic development and deforestation in the Brazilian Amazon with the objective of providing evidence for the transition from a boom-and-bust to an EKC pattern in the Amazon. First, we confirmed the reversal of the boom-and-bust development pattern using different socioeconomic data than Weinhold et al. (2015) and Caviglia-Harris et al. (2016). Second, the fine analysis of the relationship between socio-economic and deforestation variables produced evidence for the emergence of an EKC. Finally, we discussed the policies implications of such evolution of the deforestation and socio-economic development pattern, especially with regard to the recent advancements in environmental governance in Brazil.

\section{Materials and methods}

\subsection{Data processing}

We crossed socio-economic data from full-population censuses in 2000 and 2010 provided by the Brazilian Institute of Geography and Statistics at census sector scale (IBGE, 2010) with the PRODES deforestation maps provided by the Brazilian National Institute for Space Research (INPE) (INPE, 2014). As IBGE raw data are produced for 37,295 census sectors covering the entire Amazon, whereas there are only 775 Amazonian municipalities, the census sector data presents a finer spatial scale than the municipal data traditionally used in socio-economic studies (e.g. Rodrigues et al., 2009, Celentano et al., 2012 and Weinhold et al., 2015).

Both datasets were projected on a 10x10 km regular grid for two reasons (Tritsch and Le Tourneau, 2016). First, the number of census sectors in the Brazilian Amazon grew rapidly from 11,850 to 37,295 sectors during the study period, thus limiting the relevance of an inter-annual comparison at sector level. Second, while deforestation decreased dramatically in the 2000s, we considered the original sector level of the census was not adequate to capture the spatial variability of deforestation across the Amazon, especially in rural areas where census sectors can be very large. The cell's area $\left(100 \mathrm{~km}^{2}\right)$ was defined to round down the average area of a census sector as observed in $2010\left(137 \mathrm{~km}^{2}\right)$.

For each cell in the grid ( $n=51,642$ cells), we first retrieved the areas of forest, non forest (i.e. mainly Cerrado areas), deforestation (with the corresponding year), water, and cloud from PRODES data. We then discarded cells with large unobserved areas, in other words, a cell was only analyzed if the sum of areas of forest, deforested land and water accounted for more than $70 \%$ of the cell's area. Additionally, it is worth mentioning that urban areas were kept in the analysis although they may induce some artifacts due to their high population densities and incomes associated to low deforestation activity. We felt that the bias caused 
by these urban areas is limited as we applied the same methods on both datasets (2000 and 2010). Overall, discarding urban areas would remove a large part of the Amazonian population and wealth, thus limiting the interest of the study.

The final grid thus contains 30,693 cells for which we computed two deforestation indices also used by Rodrigues et al. (2009):

-Deforestation extent is the cumulative proportion of deforestation in a cell in 2000 and 2010;

- Deforestation activity is the proportion of land area in a cell that has been cleared during the preceding three years, i.e. 1998-2000 and 2008-2010 time periods.

In addition, we computed different measures of socio-economic development by referring to the standard of living (income per household in Brazilian Real, R\$), literacy (proportion of literate heads of household) and access to basic services such as sanitation (proportion of households with toilets). To do this, we proportionally shared out the socio-economic data from each sector across all underlying corresponding cells. As an example, a sector of 1000 inhabitants of which $25 \%$ of its area covers a cell $A$ and $75 \%$ covers a cell $B$ will attribute 250 inhabitants to cell $A$ and 750 inhabitants to cell $B$. We did not use the HDI as it is only calculated at the municipal scale but not at the census scale. Finally, to avoid any artifact in the socio-economic data, all cells crossing a census sector with No data value were deleted so that the final database contains $n=24,068$ cells in 2000 and $n=23,123$ cells in 2010 .

\subsection{Boom-and-bust analysis}

To ensure continuity with the study of Rodrigues et al. (2009) who evidenced the boom-andbust development pattern in 2000, we classified the cells in the same seven frontier classes ( $A$ to $G$ ) based on both the extent of deforestation and deforestation activity (Fig. 1). The classes range from pre-frontier classes $(A, B)$ characterized by a limited area of deforestation and low deforestation activity, through active frontier classes $(C, D, E)$ with increasing area of deforestation and high deforestation activity, up to post-frontier classes $(F, G)$ where the extent of deforestation is high but deforestation activity is low. These seven classes represent the different stages of the process of frontier expansion under which wildlands are converted into highly anthropized areas, as conceptualized by DeFries et al. (2004) and Foley (2005). The stabilized cells with a moderate extent of deforestation and low deforestation activity remain unclassified in this conceptualization of frontier expansion.

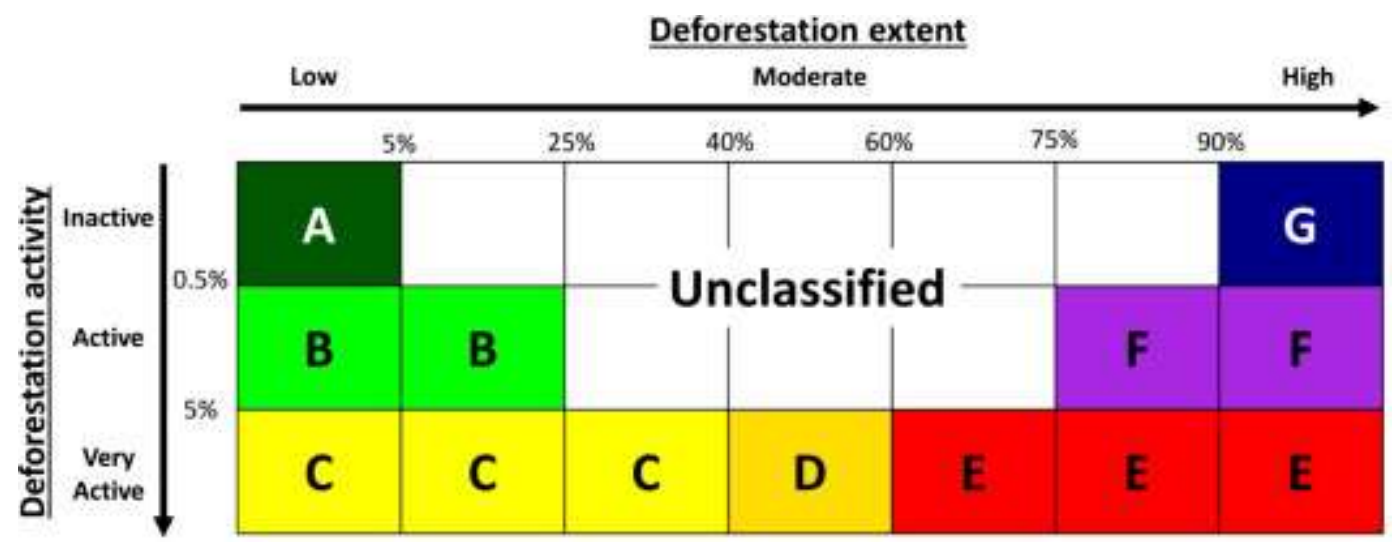


Fig. 1. Definition of frontier classes based on the extent of deforestation and deforestation activity used to classify cells (inspired by Rodrigues et al., 2009).

To test the existence of a boom-and-bust development pattern, we plotted the socioeconomic development variables against the frontier classes in 2000 and 2010 and evaluated the statistical differences among the classes using the Kruskal-Wallis test and Tukey's honestly significant difference test. The first test verifies whether samples originate from the same distribution while the second is used in post-hoc analysis to test if mean values of two samples are significantly different.

\subsection{Environmental Kuznets curve analysis}

While the boom-and-bust hypothesis analyses a pattern of socio-economic development depending on deforestation, the EKC explores how socio-economic development acts on deforestation. Its application to tropical deforestation has long been debated and appears to be somewhat controversial (Koop and Tole, 1999 and Choumert et al., 2013). There is a disagreement between researchers who consider the EKC relevant and present it as one of the hypothesis explaining the forest transition process (Barbier et al., 2010, Mather et al., 1999, Rudel et al., 2005 and Culas, 2012) and others who dismiss the EKC (Stern, 2004). In this regard, the lack of consideration for institutional factors while they play an important role in the implementation of environmental policies and, consequently in the relationship between environmental quality and socio-economic development, has especially been emphasized as a major limitation of EKC analysis (Bhattarai and Hammig, 2001, Bhattarai and Hammig, 2004 and Culas, 2007).

From a methodological point-of-view, most critics raised several empirical shortcomings due to the choices made by authors about the statistical properties of the data used, the econometric strategy, the measure of deforestation, the geographical area and the presence of control variables (Stern, 2004 and Choumert et al., 2013). For example, while panel data should be preferred, the EKC is usually analyzed in cross-sectional analysis that fails to account for the wide diversity of physical and social characteristics across countries (Koop and Tole, 1999). In the present study, we considered the Brazilian Amazon cross-sectional data appropriate to analyze the EKC relationship between deforestation and socio-economic development because we compared changes that occurred between two periods in a regional area subject to the same public policies.

Additionally, deforestation is sometimes considered as irrelevant to monitor a decline in environmental degradation since it is usually seen as an irreversible process, as in the PRODES data where forested areas are under continuous degradation since forest regeneration is not taking into account. However, deforestation still represents the main threat to the environment in the Amazon and the major source of greenhouse gas emissions (Baccini et al., 2012). This is why we considered deforestation activity as a relevant indicator of environmental degradation.

In view of these concerns, it is worth noting that the present study is more engaged on a general argument about the evolution of the relationship between deforestation and socio- 
economic development in the prism of environmental governance than in a detailed discussion of the EKC theory in an empirical approach.

Concretely, we statistically tested the hypothesis of the emergence of an EKC in the Brazilian Amazon by measuring the relationship between deforestation activity and income per household based on a quadratic model (Eq. (1)) where DEF is deforestation activity and INC is income per household. Koop and Tole, 1999 and Choumert et al., 2013. As suggested by Choumert et al. (2013), we considered that an EKC relationship exists if the coefficient is positive for income $\left(b_{1}>0\right)$ and negative for the squared income $\left(b_{2}<0\right)$.

equation(1)

$D E F=\beta_{0}+\beta_{1} I N C+\beta_{2} I N C^{2}+\epsilon D E F=\beta 0+\beta 1 I N C+\beta 2 I N C 2+\epsilon$

We then attempted to quantify the turning point of the EKC, i.e. the inflection point at which environmental degradation starts declining (Koop and Tole, 1999 and Dinda, 2004). We thus focused our analysis on the identification of (i) an income threshold above which socioeconomic growth does not appear anymore to be a driver of deforestation and (ii) a deforestation threshold above which new clearings do not appear to be a vehicle for economic growth.

In this regard, the frontier classification proposed by Rodrigues et al. (2009) is not appropriate since it is not inclusive. Indeed, cells with a moderate extent of deforestation and low deforestation activity remain unclassified (white cells in Fig. 1). However they are expected to have increased in importance in the 2000s due to the decline of deforestation and thus deserve to be monitored with special care to identify a possible change in the environmental and socio-economic development pattern. For this reason, we chose an inclusive approach including all the cells in the database.

To identify the income threshold, we first sorted all cells according to income per household and grouped them by percentile. We then plotted the deforestation activity (in \%) for each group of cells and computed a moving average in order to outline the trends. To ensure the best possible comparison between the 2000 and 2010 periods, we calculated the income per household relative to the Brazilian minimum wage (i.e. $151 \mathrm{R} \$$ in 2000 and $510 \mathrm{R} \$$ in 2010) (Salario minimo, 2016).

Finally, we defined a deforestation extent threshold using the ratio of the income per household in inactive cells (deforestation activity $\leqslant 0.5 \%$ ) to active and very active cells (deforestation activity $>0.5 \%$ ) for different classes of deforestation extent. With this ratio, we aimed to identify a deforestation extent threshold above which the income per household in inactive areas becomes greater than in areas of active to very active deforestation. We focused the analysis on areas with deforestation extent values ranging from 10 to $90 \%$ since we considered that inactive cells are over-represented beyond these thresholds. To define classes in that range, we sorted the deforestation extent values for inactive cells (which are less represented in the database) and grouped them by percentile so that each class is represented by a fix number of at least $N$ inactive cells and a variable number of $K$ active and very active cells ( $K$ being usually greater than $N$ ). We then calculated the ratio between the median income per household in inactive cells and active + very active 
cells and outlined the trends with a moving average. Additionally, we also computed the ratio between the median income per household in inactive cells with the median income of the $N$ richest and $N$ poorest active cells (in terms of income per household) in order to (i) limit any bias related to over-representation of a class (in cases where $K \gg N$ ) and (ii) define the full range of ratio values for each class of deforestation extent and thus provide a confidence interval to the results.

\section{Results}

\subsection{The stabilization of the frontier and the end of the boom-and-bust development pattern}

We first mapped the frontier classes (A-G) defined in Fig. 1 according to deforestation activity and deforestation extent (Fig. 2). These maps illustrate the stabilization of the frontier between 2000 and 2010. The active frontier areas (classes C, D and E) decreased dramatically from 4310 to 1268 cells (i.e. a $70 \%$ decrease). In 2010, most of the active cells were located in Pará state along the Cuiabá-Santarém (BR-163) and Belém-Brasília roads. Other smaller active frontiers are located to the east of Rondônia (along the BR-364 road), in Roraima and Mato Grosso states. The decrease in active frontier areas corresponds to an increase in post-frontier areas (from 1425 to 3010 cells for F and G classes) and stabilized areas (from 3530 to 7265 unclassified cells). Actually, most of the active frontier areas of the "arc of deforestation" in 2000 became stabilized or post-frontier areas in 2010. 


\section{Year 2000}

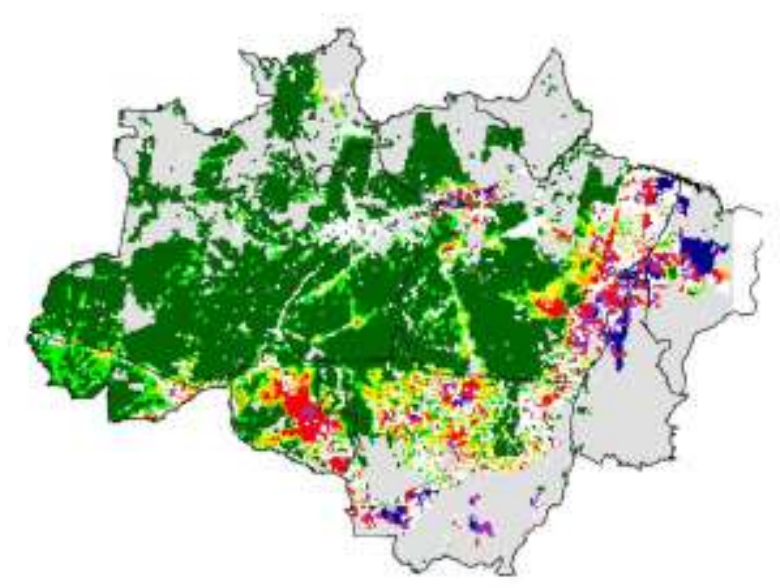

\section{Year 2010}

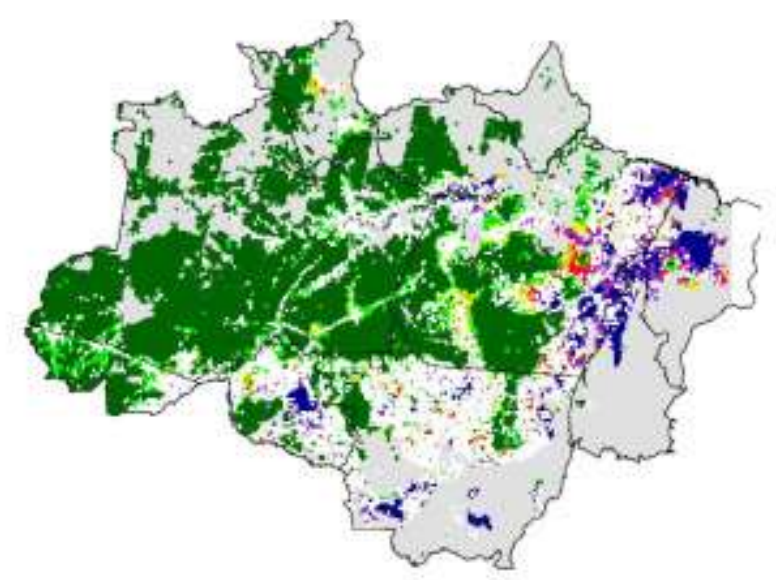

\section{Frontier classes}

A $\square$ B $\square$ C $\square$ D $\square$ E $\square$ F $\square$ G Unclassified

Fig. 2. Maps of frontier classes in 2000 and 2010. Classes range from pre-frontier (A, $B)$ to active frontier $(C, D, E)$ and post-frontier $(F, G)$ classes. Non forest areas are represented in dark grey.

To test the boom-and-bust hypothesis, we then plotted the socio-economic development variables in 2000 and 2010 against the frontier classes used by Rodrigues et al. (2009) from a cross sectional perspective (Fig. 3). Although all socio-economic measures increased significantly at each frontier stage between the two dates, the development pattern changed dramatically. In 2000, a boom-and-bust trend can be observed for all variables. The post-frontier class (G) presents a lower level of socio-economic development than the active frontier classes (C, D, E) and a similar level to that of the B pre-frontier class. This was statistically confirmed by the Tukey's honestly significant test and thus confirms the results obtained by Rodrigues et al. (2009) at municipal level, as it also validates our approach based on a regular grid and census sector data. 

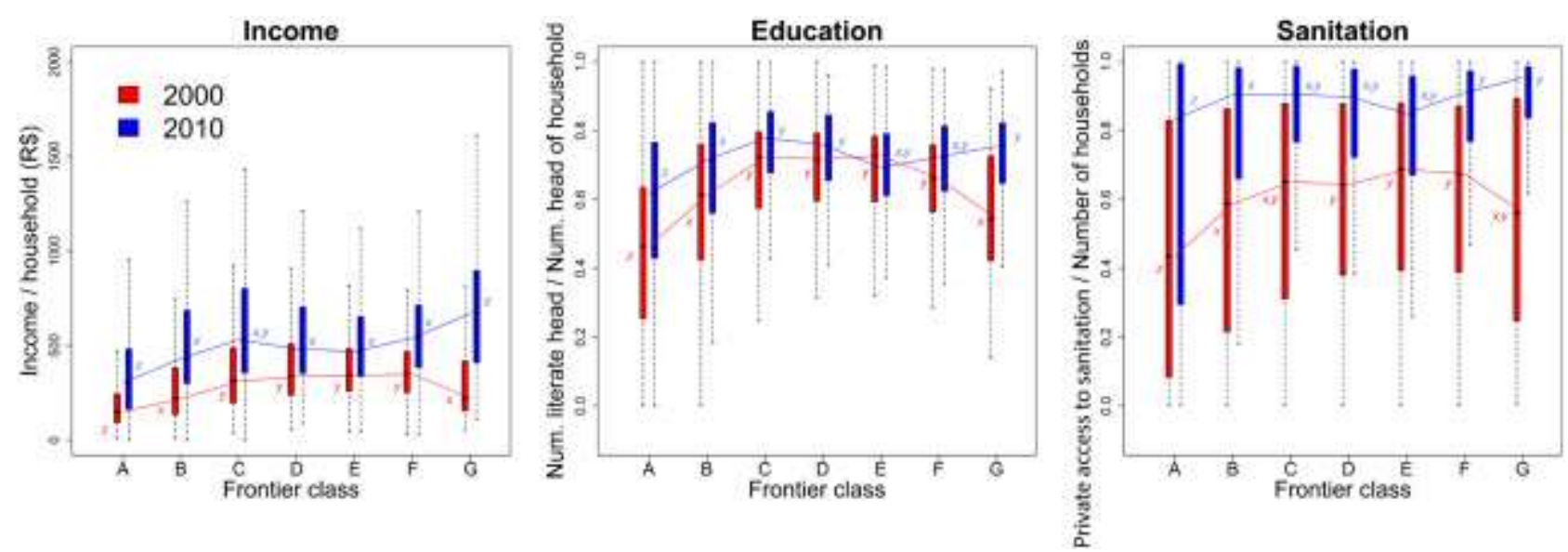

Fig. 3. Variation in income per household, literacy and access to basic sanitation services in 2000 (in red) and 2010 (in blue) across the frontier classes. Dots indicate median values and bars indicate first and third quartiles. Dashed lines represent extreme values. All variables present significant variation across the frontier classes (Kruskal-Wallis: $P<0.0001)$; classes that do not have a letter $(u, v, w, x, y, z)$ in common differ significantly (Tukey's honestly significant difference test: $P<0.05$ ).

Conversely, in 2010, the post-frontier areas (F, G) had better levels of socio-economic development than the pre-frontier (A, B) and active frontier (C, D, E) areas, indicating that the last decade was marked by the end of the boom-and-bust socio-economic development pattern in the Brazilian Amazon. The results we obtained with socio-economic data at census sector level thus confirm the analysis of Weinhold et al. (2015) and Caviglia-Harris et al. (2016) at municipal level. Nonetheless, while Tukey's honestly significant test logically does not evidence any boom-and-bust pattern ( $G$ differs significantly from classes $A$ and $B$ ), neither does it confirm a boom pattern, since class $G$ does not significantly differ from class C, for example.

These results question the reasons for the reversal of the boom-and-bust development pattern. Actually, Weinhold et al. (2015) recently suggested that the bust observed in 2000 could be due to a spatial bias. Our maps of the frontier stages in 2000 and 2010 (Fig. 2) tend to support this hypothesis. Indeed, $44 \%$ of post-frontier cells in 2000 were spatially clustered in the state of Maranhão, which had a significantly lower level of development than other states in the Amazon and thus pulled the average socio-economic measures of post-frontier areas downwards. In contrast, ten years later, post-frontier areas expanded to other states, mainly Rondônia ( $11 \%$ of total G cells), Mato Grosso (22\%) and Pará $(30 \%)$ and better represented the spatial variability of socio-economic conditions across the entire arc of deforestation. However, it also increased the within-class variance and decreased the between-class separability, explaining why the Tukey's test was not conclusive for 2010. In this regard, the end of the boom-and-bust development pattern observed in the cross sectional analysis may appear to be the result of a "business as usual" expansion of the deforestation frontier.

\subsection{Emergence of an environmental Kuznets curve in the Brazilian Amazon}

A priori, a scenario with a higher level of socio-economic development in post-frontier areas (highly deforested cells) may encourage new clearings in the pre- and active-frontier areas 
and thus result in a deforestation boom. Nonetheless, the last decade has been characterized by an unprecedented decline in deforestation (Nepstad et al., 2009) suggesting that enhanced socio-economic development may actually be related to improved environmental preservation. Such a scenario has long been theorized by the environmental Kuznets curve (EKC) hypothesis, which states that environmental degradation increases in the early stages of socio-economic development until primary needs are met and decreases in later stages as the economy develops and create wealth for populations (Dinda, $\underline{2004}$ and Pfaff and Walker, 2010).

We measured the relationship between deforestation activity and income with Eq. (1). The results confirmed the hypothesis of a significant EKC relationship between income and deforestation (Table 1). Actually, we found an EKC for both 2000 and 2010, indicating that the transition to an inverted $\mathrm{U}$-shaped relationship between deforestation and socioeconomic development was already underway at the end of the 1990s, i.e. before the deforestation decline observed from the mid-2000s.

Table 1. Coefficients of the quadratic regression model between deforestation activity and income for 2000 and 2010.

\begin{tabular}{|c|c|}
\hline 2000 & 2010 \\
\hline $0.985437 * * *$ & $0.322695 * * *$ \\
\hline$-0.029710 * *$ & $-0.040279 *$ \\
\hline
\end{tabular}

Significance at the $0.1 \%$ level. We considered that an EKC relationship exists if the coefficient is positive for income $\left(b_{1}>0\right)$ and negative for the squared income $\left(b_{2}<0\right)$ Choumert et al. (2013).

The emergence of the EKC relationship in the Brazilian Amazon implies the existence of a turning point above which environmental degradation starts declining. Koop and Tole, 1999 and Dinda, 2004. In this context, we attempted to identify thresholds in both income per household and extent of deforestation.

\subsubsection{Income threshold above which deforestation activity starts declining}

Fig. 4 depicts the deforestation activity as a function of income, and hence the EKC. It emphasizes a positive relationship between deforestation and income in low income areas. In the case of high incomes, the relationship is stable in 2000 and negative in 2010. For 2000, the curve does not illustrate the EKC hypothesis but the plateau explains why we statistically identified an EKC trend in 2000 (Table 1). In 2010, the inverted U-shaped curve is typical of an EKC and illustrates a decoupling between deforestation and socio-economic development in the Brazilian Amazon as also expressed by Caviglia-Harris et al. (2016). 

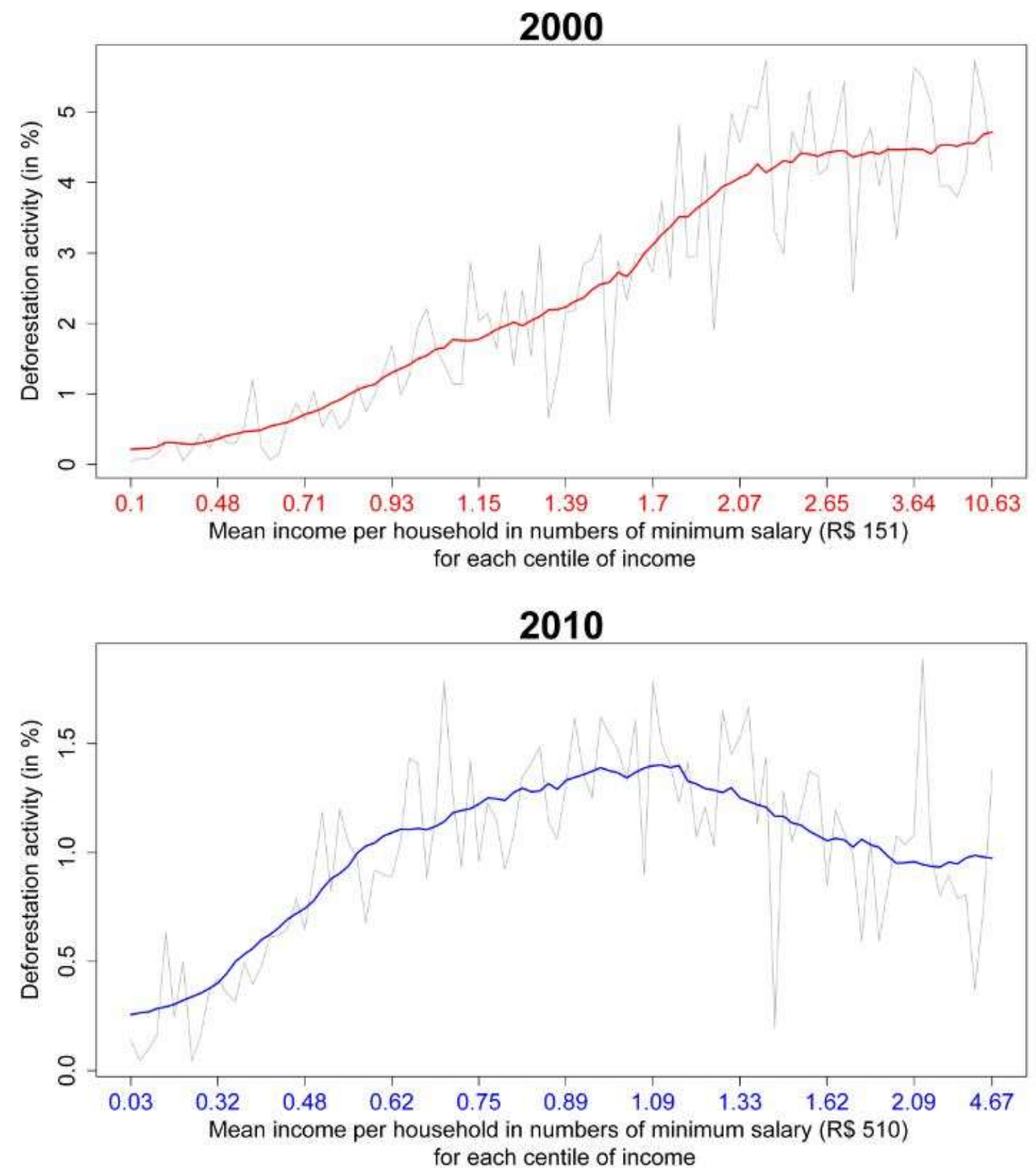

Fig. 4. Deforestation activity as a function of mean income per household in 2000 and 2010. In 2000, the curve illustrates a positive relationship between income and deforestation activity. In 2010, this relationship follows an inverted U-shaped, evidence of the emergence of the EKC: beyond a income threshold of one minimum wage per household, deforestation activity begins to decrease.

Concerning the income threshold, in 2000, our results (Fig. 4) indicate an inflection point over an income per household equal to 2.5 times the Brazilian minimum wage, above which the relationship between income and deforestation reaches a plateau at high levels of deforestation activity. In 2010, the turning point is observed around one minimum wage per household. Above this income value, deforestation activity decreased significantly. 
These results raise important issues about the relative responsibility of low and high income populations in explaining deforestation. Actually, whereas $85.3 \%$ of the total deforested area in the Amazon in the 1998-2000 period was carried out in cells where the mean income per household was higher than one minimum wage, this proportion fell to $48.9 \%$ in the period 2008-2010. The growing importance of low income populations in total deforestation is first explained by the rapid increase (from 33.9\% to $56.7 \%$ between 2000 and 2010 ) in the number of cells with low income values (< one minimum wage) due to the fact that the minimum wage evolved faster than inflation in the 2000s (Cornia, 2014). However, the increase in average deforestation activity (from $0.61 \%$ to $0.85 \%$ during the same period) in low income cells should not be overlooked, since it is evidence of profound changes in the drivers and actors of deforestation in the Brazilian Amazon, as also evidenced by Godar et al. (2014).

\subsubsection{Deforestation extent threshold above which incomes in inactive areas become higher than in areas subjected to active deforestation}

To define a threshold of deforestation extent, we analyzed the ratio between the median income in inactive cells (deforestation activity $\leqslant 0.5 \%$ ) and active or very active cells (deforestation activity $>0.5 \%$ ) for different ranges of deforestation extent ( $\underline{\text { Fig. } 5}$ ).
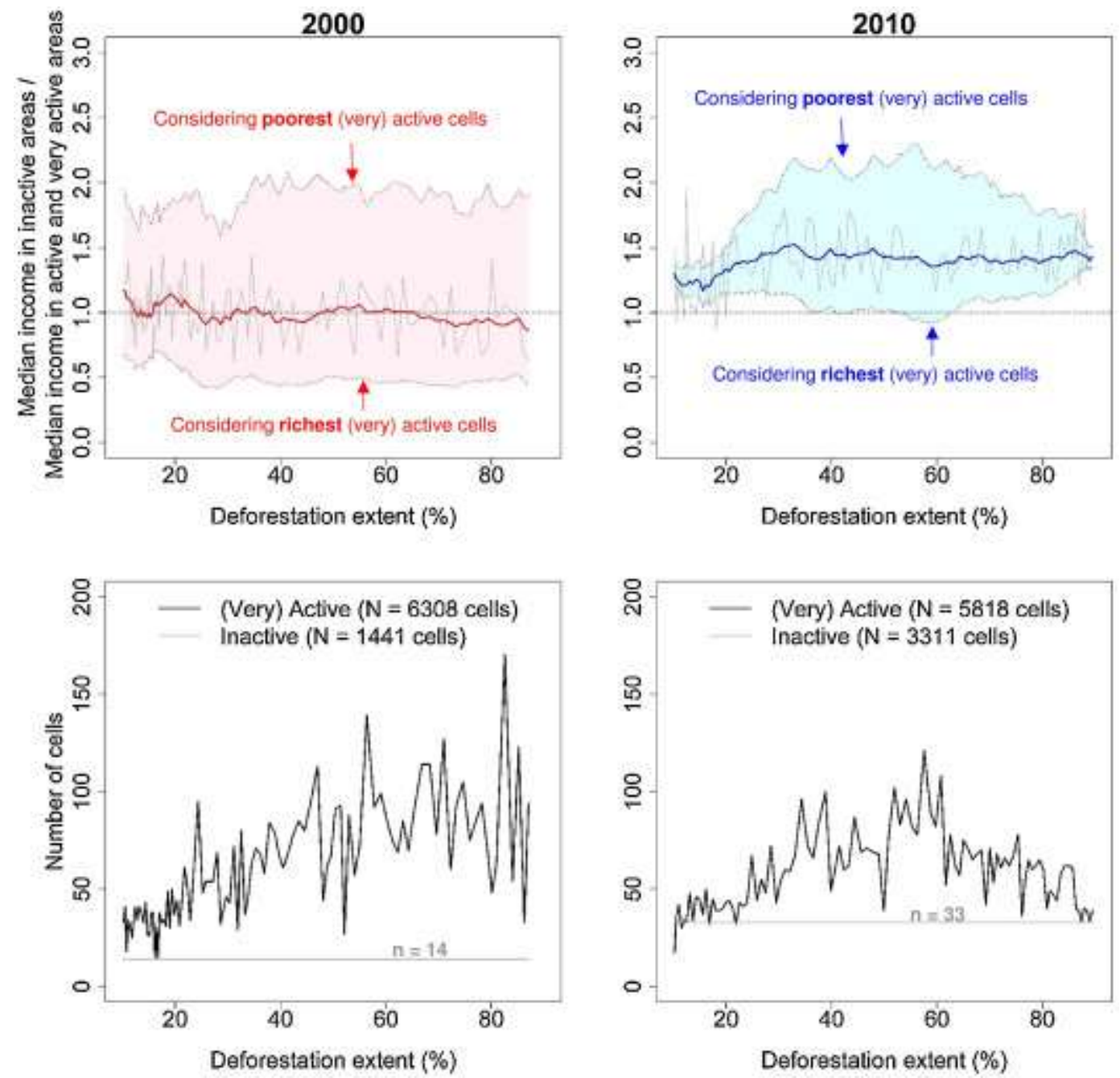
Fig. 5. Ratio between the median income in inactive cells (deforestation activity $\leq=$ $0.5 \%$ ) and active + very active cells (deforestation activity $>0.5 \%$ ) for different ranges of deforestation extent. High ratio values $(>1)$ indicate that income per household in inactive cells is greater than in active + very active cells. Dashed lines represent the ratio between the median income per household in inactive cells with the median income of the $n$ richest and $n$ poorest active + very active cells. Lower diagrams indicate the number of inactive or active + very active cells for each class of deforestation extent. The minimum number of cells by class of deforestation extent is $n=14$ and $n=33$ for 2000 and 2010 respectively.

In 2000 , low values $(\simeq 1)$ indicated no significant difference in income per household in areas undergoing active deforestation when compared with inactive ones, independently of deforestation extent. In contrast, in 2010, high ratios (>1) appeared for every range of deforestation extent so that the incomes per household were always higher in inactive areas than in areas undergoing active deforestation. So we cannot identify a deforestation extent threshold above which incomes in inactive areas become higher than in active areas. This assertion is even true when the ratio is computed comparing the income of all inactive cells with the richest active and very active cells only.

This result is very important as it puts an end to the assumption that active deforestation is necessary to ensure socio-economic development in the Brazilian Amazon. Actually, it also emphasizes the importance of active deforestation as an indicator of a precarious economic situation what corroborates our previous conclusions.

\section{Discussion: emergence of the EKC as a result of a transition in environmental governance}

The emergence of the EKC inverted U-shaped relationship between deforestation and socioeconomic development in the Brazilian Amazon is the result of a transition in environmental governance that occurred over the last decade to ensure a move toward land use sustainability (Culas, 2007 and Galford et al., 2013). Ambitious and effective policies at national, state and local levels to (i) contain deforestation (e.g. the Soy and Beef Moratorium or the Action Plan for Prevention and Control of the Legal Amazon Deforestation, PPCDAm) (Rudorff et al., 2011, Gibbs et al., 2015 and Le Tourneau, 2015) and (ii) support socioeconomic development (e.g. different nationwide social policies such as the Bolsa Familia, Fome zero, Luz para todos and rural retirement programs ( Fenwick, 2009) have shaped a new environmental and socio-economic development pattern in the Amazon.

Here we discuss the different dimensions of this transition and policy implications that deserve to be put into perspective with regard to the emergence of an EKC for the specific case of deforestation in the Brazilian Amazon.

\subsection{Increased investments in environmental preservation}

The EKC is linked to effective policies that imply sufficient direct investment in environmental preservation (Culas, 2007 and Dinda, 2004). In the case of deforestation in 
the Brazilian Amazon, efforts have primarily been oriented toward the reinforcement of command-and-control policies. These efforts required the investment of considerable capital stock, which was made available after the expansion of the commodity-oriented agricultural model. The rapid economic growth in Brazil since the 1990s made it possible to bank ambitious programs to ensure secure property rights and private property registration, to implement an efficient remote sensing-based deforestation monitoring system, to establish restrictions on access to credit and to support the expansion of a network of protected areas (Nepstad et al., 2014). It also enabled the introduction of environmental taxes such as the Ecological Tax over Merchandise and Services Circulation (ICMS-Ecológico, Imposto sobre Circulação de Mercadorias e Serviços), which can be conceptualized as a system of compensation for municipalities where land use is restricted in specific areas for environmental reasons. In this regard, rents resulting from past deforestation were reinvested in physical, human and natural capital so that forest resources were replaced by these other inputs to sustain economic growth ( Caviglia-Harris et al., 2016).

Nonetheless, environmental preservation efforts to date were mainly directed towards reducing deforestation. One should keep in mind that despite the spectacular decrease in deforestation, others forms of environmental degradation still persist in the Brazilian Amazon. In this regard, we suggest that particular attention should be paid to the forest degradation process in future EKC studies, because of its critical magnitude in the Brazilian Amazon (Souza et al., 2013, Aragão and Shimabukuro, 2010, Chaplin-Kramer et al., $\underline{2015}$ and Bustamante et al., 2016). Similarly, forest regeneration should also be taken into account since it partially counteracts the deforestation effect, especially with regards to greenhouse gas emissions. Furthermore, forest regeneration can mark the beginning of a forest transition dynamic (Rudel et al., 2010, Rudel et al., 2005 and Barbier et al., 2010) which may represents the next path towards environmental preservation after the emergence of the EKC (Pfaff and Walker, 2010 and Culas, 2012).

\subsection{Emergence of market-oriented forms of regulation}

An EKC also appears when command-and-control policies are associated with marketoriented forms of regulation (Dinda, 2004). The implementation of the Soy and Beef Moratorium through which traders agreed not to purchase soy and cattle from newly deforested lands in the Brazilian Amazon (Rudorff et al., 2011, Nepstad et al., 2014 and Gibbs et al., 2015) is a concrete example of the way civil society managed to establish market-oriented policies to put pressure on an agro-industrial sector to satisfy society's increased consideration of the environment.

A way to encourage new market-oriented forms of regulation consists in assigning an economic value to natural resources, which can then foster the emergence of the EKC (Dinda, 2004). In this sense, the initiatives from REDD (Reducing Emissions from Deforestation and forest Degradation) could provide financial incentives to avoid deforestation and so flatten the inverted U-shaped curve of the EKC (Culas, 2012).

Different initiatives of payments for ecosystem services (PES) have already been implemented in the Brazilian Amazon, for example the Bolsa-Floresta program in humanoccupied protected areas of the State of Amazonas and the REDD+ pilot program PAS 
(Projeto Assentamentos Sustentaveis na Amazonia) in the Trans-Amazonian Highway. A wider implementation of such initiatives should be encouraged in order to mix "carrot and stick" policies to promote forest conservation ( Börner et al., 2014).

\subsection{Emergence of an intensive agricultural model}

In neoclassical growth theory, long-term growth rates depend on technical progress (Caviglia-Harris et al., 2016). This may combine with environmental preservation and the emergence of the EKC if investments are made to promote technological progress and replace obsolete technologies by upgraded new and cleaner ones (Dinda, 2004). This is especially true for large-scale agriculture in the Brazilian Amazon that underwent a rapid shift towards the adoption of intensive practices. In the state of Mato Grosso, the generalization of double-cropping systems is a major driver of the decoupling of deforestation and crop production (Macedo et al., 2012, Arvor et al., 2012 and Arvor et al., 2013). This is because it became more profitable for producers to invest in new technologies for use in already opened areas than to finance new forest clearings. This situation emerged for three reasons: (i) efficient command-and-control and market-oriented policies discouraged producers from investing their capital in the acquisition of new areas to be cleared, (ii) the economic situation marked by very high oil prices at the end of the $2000 \mathrm{~s}$ did not stimulate crop expansion (Richards et al., 2012) and (iii) the scarcity of high quality remaining agricultural land available for agricultural expansion, especially at the southern Amazon's agricultural frontier (Spera et al., 2014).

However, although the intensification process may have reduced pressure on forests, it is also connected with social and environmental degradation, linked to increased inequality in land ownership (Lapola et al., 2014) and greenhouse gas emissions, soil degradation and water pollution. On the one hand, in relation to the environmental aspects of agriculture, the recent launch of the ABC plan ("Plano para uma Agricultura de Baixo Carbono") demonstrates a willingness to ensure a transition toward a more environmental friendly agricultural model. It has the following objectives: restoration of degraded pastures, promotion of integrated crop-pasture-forest systems, generalization of no-tillage practices, improvement of biological nitrogen fixation, increase in forest plantation, recycling of animal waste and adaptation to climate change. But by now, how this ambitious program will effectively be implemented remains a challenging question ( Galford et al., 2013). On the other hand, in relation to the social aspects of agriculture, the policies to resolve land tenure problems and to support smallholder agriculture - yet responsible for the major part of the food consumed in Brazil - are still too weak. They should be reinforced if Brazil wants to go ahead towards a social and environmental friendly agricultural model. For example, more agro-ecological programs promoting alternative ways of sustainable production for smallholders, such as agroforestry systems, should be supported (Tremblay et al., 2014).

\subsection{Forthcoming challenges for environmental governance}

The current context of political and economic crisis could weaken the Brazilian institutional and financial capacities to ensure environmental preservation in the Amazon. On the one hand, recent statistics provided by INPE already indicate that deforestation rates get in a plateau with small variations up and down which could be exacerbated by the political 
instability caused by Presidential impeachment process (Rodrigues-Filho et al., 2015) and the revision of the forest code (Soares-Filho et al., 2014 and Verburg et al., 2014). On the other hand, current very low oil prices and high exchange rates between US\$ and R\$ could encourage agricultural expansion by reducing the costs for forest clearing and crop production. Moreover, maintaining and strengthening the costly command-and-control environmental policies may become challenging in an unfavorable economic context.

In this regard, it is worth mentioning that, in their seminal paper about EKC, Grossman and Krueger (1995) estimated that the EKC turning point where environmental degradation starts declining usually comes when a country reaches a per capita GDP of US\$ 8000. After a rapid increase of the GDP in the 2000s, Brazil has reached this threshold in 2008 (TWB Group, 2016), i.e. approximately (but maybe coincidentally) at the same time period we identified the emergence of the EKC. As a consequence, considering how the more recent decline of the Brazilian GDP per capita (from US\$13,000 in 2013 to US\$8540 in 2015) may affect the transition in environmental governance is a worrying issue.

Additionally, even though the structure of production of the agricultural model is changing rapidly, it is not being accompanied by equivalent changes in the structure of consumption. In this case, "EKC may actually record displacement of dirty industries from developed economies to less developed economies" ( Dinda, 2004). Indeed, although Brazilian efforts to contain deforestation in the Amazon have produced promising results, these were not achieved at the expense of the growth of the Brazilian agricultural sector. This sector continues to expand in other Brazilian regions: the soybean agricultural frontier has now reached the Cerrado areas of MATOPIBA (i.e. Maranhão, Tocantins, Piaui, Bahia states) (Eloy et al., 2015, Macedo et al., 2012 and Richards et al., 2014) which is targeted by investors from Brazil and abroad ( Ofstehage, 2015 and EMBRAPA, 2016). So particular attention should be paid to deforestation of the Cerrado biome when defining future environmental policies. Recent studies also evoked the emergence of a new soybean frontier in Southern Africa, where Brazil is reinforcing its economic presence ( Gasparri et al., 2015, Clements and Fernandes, 2013, Seibert, 2011, Oliveira, 2015 and Shankland and Gonalves, 2016).

\subsection{Environmental governance fosters the emergence of the EKC}

In the Brazilian Amazon, despite the recent political crisis, the governance structures have improved and become much more solid than a few decades ago. As we have seen, it has significantly affected the Brazilian Amazon deforestation process and the path toward land use sustainability while the social policies and cash transfer programs have enabled several millions of Brazilians to leave poverty behind (Barrientos, 2013 and Fenwick, 2009).

For these reasons, besides the traditional mechanisms of causality normally claimed in the EKC literature such as the transformation of the structure of the economy (e.g. agricultural intensification and the substitution of forest products by alternative sources (Cropper and Griffiths, 1994)) or the greater emphasis that the society places on environmental value of forest resources (biodiversity, wildlife conservation, aesthetic value, and carbon sequestration, all yet still little merchantable) (Bhattarai and Hammig, 2001), the Brazilian Amazon case emphasizes the special attention that should be paid to the environmental 
governance efforts, especially through the reinforcement of institutions, to explain the EKC for deforestation.

In fact, institutional factors and macroeconomic policies can reduce the amplitude of the EKC and consequently the environmental price of economic growth (Culas, 2007, Bhattarai and Hammig, 2001 and Bhattarai and Hammig, 2004). Factors such as improved literacy, secure property rights, better enforcement of law and contracts, and citizen participation in decision-making can weaken the income effect on the EKC hypothesis and so flatten the EKC curve. Thus the society can avoid potential environmental catastrophes while achieving sustainable growth (Torras and Boyce, 1998, Panayotou, 1997, Bhattarai and Hammig, 2001 and Bhattarai and Hammig, 2004). So, the EKC literature for tropical deforestation should definitely pay more attention to the governance and institutions which can directly foster the emergence and flattening of the EKC.

\section{Conclusion}

The historical Amazonian pattern of boom-and-bust development was reversed between 2000 and 2010. The depletion of the Amazonian forest is no longer linked with a socioeconomic collapse as predicted by the boom-and-bust scenario. In all cases, post-frontier regions present better socio-economic indicators than pre-frontier and frontier regions. This sounds consistent as today the economic activities of the post-frontier regions are dominated by intensive agricultural production of commodities including soybean. Yet, the soy cultivation is associated with increased household incomes but also increased inequality among producers (Weinhold et al., 2013 and Lapola et al., 2014). This modern economy is fully integrated, with national and international investments, markets and improvement programs, and has enabled an efficient transition to intensive agriculture. Although these post-frontier areas remain vulnerable to international (commodity prices) and national (exchange rates) economic conditions, they now have a sufficiently strong economic base to avoid a future economic collapse. So the re-emergence of a boom-and-bust development pattern is very unlikely.

Our data shows profound changes in the Brazilian Amazon since we evidenced the emergence of an environmental Kuznets curve as a new environmental and socio-economic development pattern in the Amazon. It bears witness to a rupture in the traditional frontier expansion cycle related to increased consideration for environmental preservation and implementation of several innovative governance measures. To date, regions subjected to active deforestation present lower socio-economic indicators than inactive (stabilized) regions, even in areas that still have a high forest cover. This is the result of the establishment of an effective environmental governance aimed at controlling deforestation and the expansion of large-scale commodity-oriented agriculture. The continuing deforestation despite environmental legislation today appears to be a sign of socioeconomic precariousness. This sounds consistent with the results from de Souza et al. (2013) who showed that areas where agriculture and livestock have low level of agrarian technology coincide with the areas of highest deforestation in the Amazon on the 20052009 period. So future social and environmental policies should concentrate more on areas where deforestation is still active, by supporting low income farmers in the improvement of their agrarian and economic situation, while achieving legal compliance (Coudel et al., 2012). 
Finally, our results raise important conceptual issues about the relationship between socioeconomic development and the environment in the tropics. First, it questions if economic growth is a mandatory stage before environmental preservation. If so, one should carefully consider the environmental benefits of the effective social policies and cash transfer programs (Barrientos, 2013 and Tritsch et al., 2015) led at federal level to enable several millions of Brazilians to leave poverty behind. Although improving socio-economic conditions led to a slight increase in deforestation activity by low income populations, it also helped them rapidly reach the turning point of the EKC. This point is of critical importance when considering the willingness of Brazil to export its environmental leadership (Ferreira et al., 2014) and its expertise in tropical agriculture to other countries that would not previously have had the necessary conditions to establish effective socio-economic programs.

The second issue refers to the role of environmental preservation as a source of economic development. To date, the efforts led by the Brazilian authorities to control deforestation have mainly been based on command-and-control punitive measures (Nepstad et al., 2014). The decoupling between deforestation and income is evidence of the capacity of farmers to rapidly adapt their economic strategies to the newly established rules. However, these strategies remain mainly oriented toward the production of raw commodities and the potential of environmental preservation as a source of income is still undervalued. It is thus necessary to support more voluntary market-oriented forms of regulations such as payments for environmental services (PES) to take advantage of the remarkable adaptability of local actors and thus achieve the ambitious objectives of environmental preservation in the Amazon.

\section{Acknowledgements}

The authors wish to thank the French National Agency for Research (ANR) which funded the DURAMAZ2 project (grant agreement ANR-11-BSH1-0003), the University SorbonneNouvelle Paris 3 for Post-doctoral Fellowship and the European Union which funded the H2020-MSCA-RISE-2015 ODYSSEA project (Project Reference: 691053). They are also grateful to the two anonymous reviewers for their constructive comments, which helped to improve the manuscript. 